\title{
Atomistic Simulation of Dislocation-Defect Interactions in $\mathrm{Cu}$
}

\author{
B. D. Wirth, V. V. Bulatov, T. Diaz de la Rubia
}

This article was submitted to Materials Research Society 2000 Symposium R, Boston, MA, December 1, 2000

\section{January 1, 2001}

U.S. Department of Energy

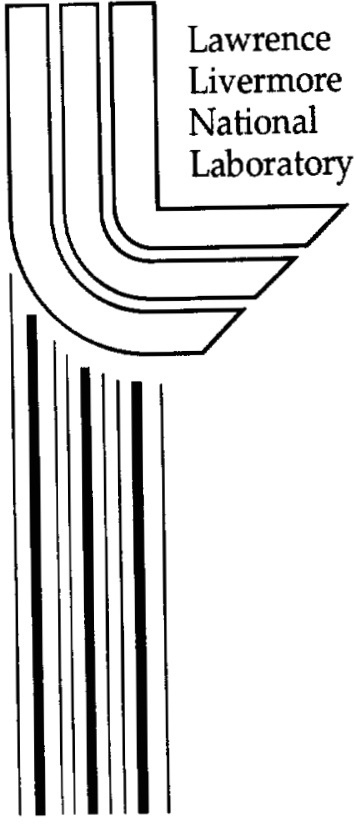




\section{DISCLAIMER}

This document was prepared as an account of work sponsored by an agency of the United States Government. Neither the United States Government nor the University of California nor any of their employees, makes any warranty, express or implied, or assumes any legal liability or responsibility for the accuracy, completeness, or usefulness of any information, apparatus, product, or process disclosed, or represents that its use would not infringe privately owned rights. Reference herein to any specific commercial product, process, or service by trade name, trademark, manufacturer, or otherwise, does not necessarily constitute or imply its endorsement, recommendation, or favoring by the United States Government or the University of California. The views and opinions of authors expressed herein do not necessarily state or reflect those of the United States Government or the University of California, and shall not be used for advertising or product endorsement purposes.

This is a preprint of a paper intended for publication in a journal or proceedings. Since changes may be made before publication, this preprint is made available with the understanding that it will not be cited or reproduced without the permission of the author.

This work was performed under the auspices of the United States Department of Energy by the University of California, Lawrence Livermore National Laboratory under contract No. W-7405-Eng-48.

This report has been reproduced directly from the best available copy.

Available electronically at http://www.doc.gov/bridge

Available for a processing fee to U.S. Department of Energy

And its contractors in paper from

U.S. Department of Energy

Office of Scientific and Technical Information

P.O. Box 62

Oak Ridge, TN 37831-0062

Telephone: (865) 576-8401

Facsimile: (865) 576-5728

E-mail: reports@adonis.osti.gov

Available for the sale to the public from

U.S. Department of Commerce

National Technical Information Service

5285 Port Royal Road

Springfield, VA 22161

Telephone: (800) 553-6847

Facsimile: (703) 605-6900

E-mail: orders@ntis.fedworld.gov

Online ordering: http://www.ntis.gov/ordering.htm

\section{OR}

Lawrence Livermore National Laboratory

Technical Information Department's Digital Library

http://www.llnl.gov/tid/Library.html 


\title{
Atomistic Simulation of Dislocation-Defect Interactions in $\mathrm{Cu}$
}

\author{
B. D. Wirth ${ }^{\mathrm{a}}$, V. V. Bulatov and T. Diaz de la Rubia, Chemistry and Materials Science \\ Directorate, Lawrence Livermore National Laboratory, Livermore, CA 94550
}

\begin{abstract}
The mechanisms of dislocation-defect interactions are of practical importance for developing quantitative structure-property relationships, mechanistic understanding of plastic flow localization and predictive models of mechanical behavior in metals under irradiation. In copper and other face centered cubic metals, high-energy particle irradiation produces hardening and shear localization. Post-irradiation microstructural examination in $\mathrm{Cu}$ reveals that irradiation has produced a high number density of nanometer sized stacking fault tetrahedra. Thus, the resultant irradiation hardening and shear localization is commonly attributed to the interaction between stacking fault tetrahedra and mobile dislocations, although the mechanism of this interaction is unknown. In this work, we present a comprehensive molecular dynamics simulation study that characterizes the interaction and fate of moving dislocations with stacking fault tetrahedra in $\mathrm{Cu}$ using an EAM interatomic potential. This work is intended to produce atomistic input into dislocation dynamics simulations of plastic flow localization in irradiated materials.
\end{abstract}

\section{INTRODUCTION}

It is well established that irradiation of metals by high-energy neutrons and ions produces significant changes in material microstructure and mechanical properties [1-5]. In low stacking fault energy face centered cubic (fcc) metals, stacking fault tetrahedra (SFT) are the primary defect observed following high-energy particle irradiation. For example, post-irradiation microstructural examination of copper irradiated at temperatures between 20 and $100{ }^{\circ} \mathrm{C}$ and doses between $10^{-4}$ and $10^{2}$ dpa reveals that approximately $90 \%$ of the high number density (about $10^{23} \mathrm{~m}^{-3}$ ) of radiation-induced defects are SFTs and that the average SFT size remains constant at about $2.5 \pm 0.5 \mathrm{~nm}[3,6]$. When deformed after irradiation, $\mathrm{Cu}$ and other low stacking fault energy fcc metals exhibit significant mechanical property degradation, including a sharp increase in yield stress, a decrease in ductility and often, plastic flow localization in the form of defect-free dislocation channels [2,5]. The formation of dislocation channels is commonly attributed to dislocation absorption of the vacancies contained in SFTs [7]. However, a concise atomistic picture of the SFT absorption mechanism is lacking. Thus, the objective of this work is to obtain atomistic insight into the interaction of SFTs with dislocations, necessary to understand radiation-induced mechanical property changes.

Computer simulation studies have been used to successfully model the production and accumulation of damage in irradiated $\mathrm{Cu}$ [8-13] and some key results of our work are briefly summarized here. Molecular dynamics (MD) simulations of displacement cascade evolution in $\mathrm{Cu}$ reveal the formation of large vacancy and self-interstitial loops [8-10]. The self-interstitial cluster loops undergo easy, one-dimensional transport [11] and are assumed to rapidly migrate away from the vacancy rich cascade region. The clustered vacancies then collapse to form SFTs,

\footnotetext{
${ }^{a}$ Corresponding author contact information: phone (925) 424-9822, fax (925) 423-7040, wirth4@llnl.gov
} 
which occurs within a few picoseconds at room temperature by a dislocation mechanism[12], consistent with that first proposed by Silcox and Hirsch [14]. Interestingly, a number of MD simulations predict that the SFT structure will not consist of perfect tetrahedron, but in most cases, will actually consist of truncated tetrahedron $[12,15]$ and in some cases, overlapping, truncated SFTs ${ }^{1}[12]$.

\section{SIMULATION METHODOLOGY}

MD simulations of the interaction and fate of moving edge dislocations in $\mathrm{Cu}$ were performed using the MDCASK code [16] and an embedded atom method (EAM) potential $[17,18]$. The elastic constants and stacking fault energy obtained with the EAM potential are provided in Table 1 . The simulations were performed in a cubic cell bounded by $\langle 111\rangle,\langle 110\rangle$ and $<112>$ faces, as sketched in Figure 1. Periodic boundary conditions are applied in the $Y=[110]$ and $Z=[1 \overline{1} 2]$ directions, while the $X=[\overline{1} 11]$ faces are free surfaces. An edge dislocation is introduced in the simulation cell by removing two (220) half-planes and equilibrating the system at $100 \mathrm{~K}$ to allow the edge dislocation, $\mathbf{b}=\mathbf{a} / 2<110>\{111\}$, to split into two Shockley partial dislocations, $\mathbf{b}=\mathbf{a} / 6<112>\{111\}$, separated by a stacking fault. SFT and overlapping, truncated SFTs were also inserted into the simulation cell on the (111) glide plane ahead of the dissociated edge dislocation. Following equilibration at $100 \mathrm{~K}$, a constant shear stress, $\tau_{\mathrm{yx}}$, is applied by superimposing a constant force in the [110] direction on the atoms in the two (111) surfaces. In the results reported here, the simulation cell was $31.2 \mathrm{~nm}$ in X, $25.5 \mathrm{~nm}$ in $\mathrm{Y}$ and either 14.0 or $38.8 \mathrm{~nm}$ in $\mathrm{Z}$ (along the dislocation line), corresponding to a dislocation density of about $8 \times 10^{14} \mathrm{~m}^{-2}$ and a SFT density of 3 to $9 \times 10^{22} \mathrm{~m}^{-3}$. The dislocation and SFT are visualized by plotting the location of atoms with high potential energy.

Table 1 - Elastic constants and stacking fault energy obtained from the EAM Cu potential $[17,18]$ used in this work.

\begin{tabular}{|l|l|}
\hline $\mathrm{C}_{11}$ & $176 \mathrm{GPa}$ \\
\hline $\mathrm{C}_{12}$ & $129 \mathrm{GPa}$ \\
\hline $\mathrm{C}_{44}$ & $82.3 \mathrm{GPa}$ \\
\hline$\mu$ & $58.8 \mathrm{GPa}$ \\
\hline Stacking fault energy & $11.4 \mathrm{~mJ} / \mathrm{m}^{2}$ \\
\hline
\end{tabular}

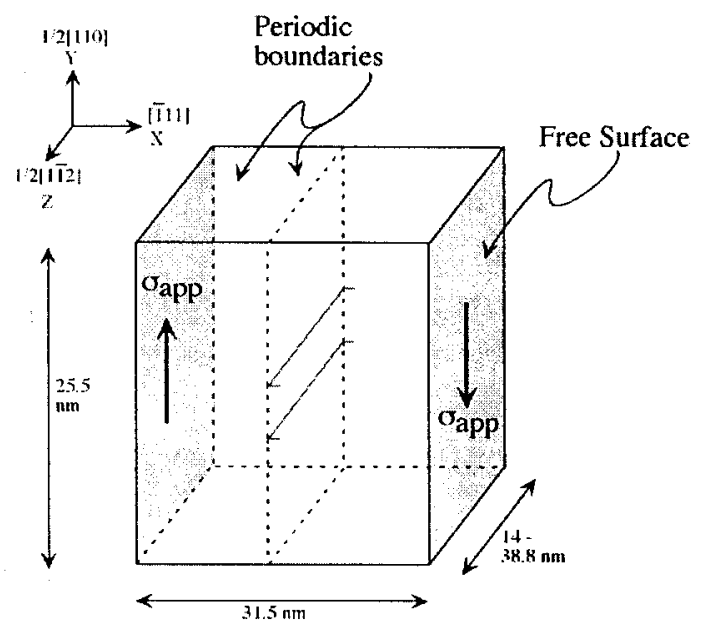

Figure 1 - Schematic view of the simulation cell and dimensions used in this work.

\footnotetext{
${ }^{1}$ A triangular vacancy platelet on a $\{111\}$ plane bounded by three $<110>$ directions forms a single SFT. A triangular vacancy platelet bounded by two $<110>$ and one $<112>$ directions forms two partial (truncated) SFTs, one above and one below the initial plane; we define this as an overlapping truncated SFT.
} 


\section{RESULTS AND DISCUSSION}

Figure 2 shows a series of MD simulation snapshots of the (111) glide plane (in [1 11$]$ projection) of the interaction between a moving, dissociated edge dislocation and a SFT which lies across the dislocation glide plane. The simulation was performed at an initial temperature of $100 \mathrm{~K}$ and an applied shear stress of $300 \mathrm{MPa}$. It is important to mention some additional details regarding this simulation. First, as shown in Table 1, the $\mathrm{Cu}$ EAM potential gives a stacking fault energy which is lower than experimental values $\left(30-40 \mathrm{~mJ} / \mathrm{m}^{2}\right)$ and results in a large equilibrium separation $(\approx 7-8 \mathrm{~nm})$ between the two Shockley partials. Second, the applied stress is significantly higher than the yield stress of copper and is used to study the fate of the interaction within readily accessible MD simulation times. Additional simulations are ongoing to characterize the effect of these (and other) variables on the results.

Figure 2 a shows the initial configuration of the edge dislocation, which is split into the two Shockley partial dislocations, and the SFT, which consists of 6 stair-rod dislocations when viewed using high potential energy atoms. Although not seen in this projection, the SFT overlaps the glide plane of the edge dislocation. Following application of the shear stress, the two Shockley partial dislocations are driven towards the SFT. Figure $2 \mathrm{~b}$ shows the position of the partial dislocations 9 ps after applying the $300 \mathrm{MPa}$ shear stress. By this time, the leading Shockley partial dislocation has reached the SFT, felt a repulsive force and bowed back away from the SFT. As the trailing partial approaches, the leading partial is forced to enter the SFT (Figure 2c). The SFT acts as a hard barrier to dislocation motion and in order for the leading partial to move past the SFT, it must noticeably bow around it, finally releasing at a critical angle of about $80^{\circ}$ (Figure 2d). By 15.5 ps (Figure 2e) the trailing partial enters the SFT, as the leading partial continues to move ahead with significant remaining curvature along its line. Interestingly, the SFT provides less resistance to the passage of the trailing partial and the shape of the trailing partial shows only a slight perturbation immediately after passing the SFT (Figure 2f).

Surprisingly, the SFT is not absorbed by the moving edge dislocation, but instead acts as a hard obstacle to dislocation motion. Following passage of the dislocation, the SFT has been sheared along the dislocation glide plane, and thus has a surface step (ledge) along three of its four $\{111\}$ faces, but remains largely intact. Qualitatively similar results are observed in simulations of the edge dislocation - SFT interaction performed with a range of applied stress from 50 to $300 \mathrm{MPa}$, different SFT separation along the dislocation line and slightly different interaction geometry. In all cases, the SFT acts as a hard barrier and despite the formation of surface steps, remains intact following dislocation passage.

However, dislocation absorption of an SFT-type defect has been observed in the case where the SFT is not perfect, but rather consists of overlapping, truncated SFTs. Figure 3 shows the results of one such simulation at $100 \mathrm{~K}$ in $\mathrm{Cu}$. In this simulation, an overlapping, truncated SFT such as formed by aging displacement cascades [12], with a spacing of $14 \mathrm{~nm}$ (along the dislocation line), is placed on the glide plane of a dissociated edge dislocation which moves under an applied shear stress of $300 \mathrm{MPa}$. Figure $3 \mathrm{a}$ shows the initial configuration of the edge dislocation, split into two Shockley partial dislocations, and the overlapping, truncated SFT (most easily visualized in $\langle 110\rangle$ projection), as represented through visualization of the atoms with high potential energy. Figure $3 b$ shows that upon contact, the leading partial absorbs vacancies from part of the overlapping truncated SFT and climbs, forming a pair of superjogs that effectively pin the leading partial as the trailing partial approaches. Figure $3 \mathrm{c}$ shows that the trailing partial catches the leading partial at the location of the overlapping SFT and superjog 
pair, climbs through absorption of the remaining vacancies in the defect and constricts at the location of the superjogs. Following defect absorption, the dislocation continues to move (Fig. $3 \mathrm{~d})$, but with a decreased mobility associated with the superjogs.

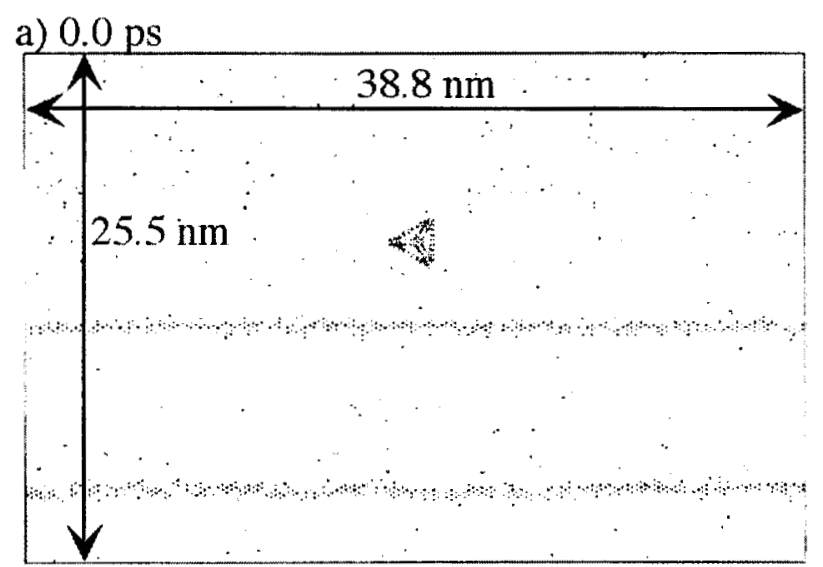

b) $9.0 \mathrm{ps}$

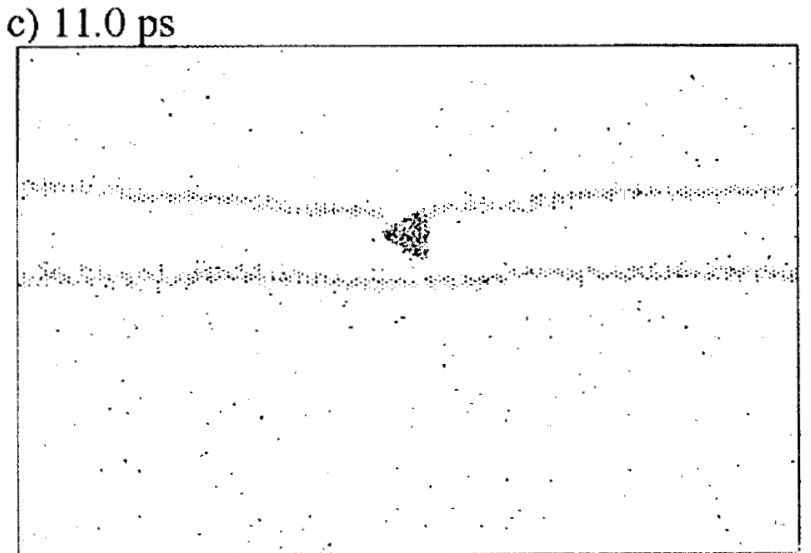

\section{e) $15.5 \mathrm{ps}$}
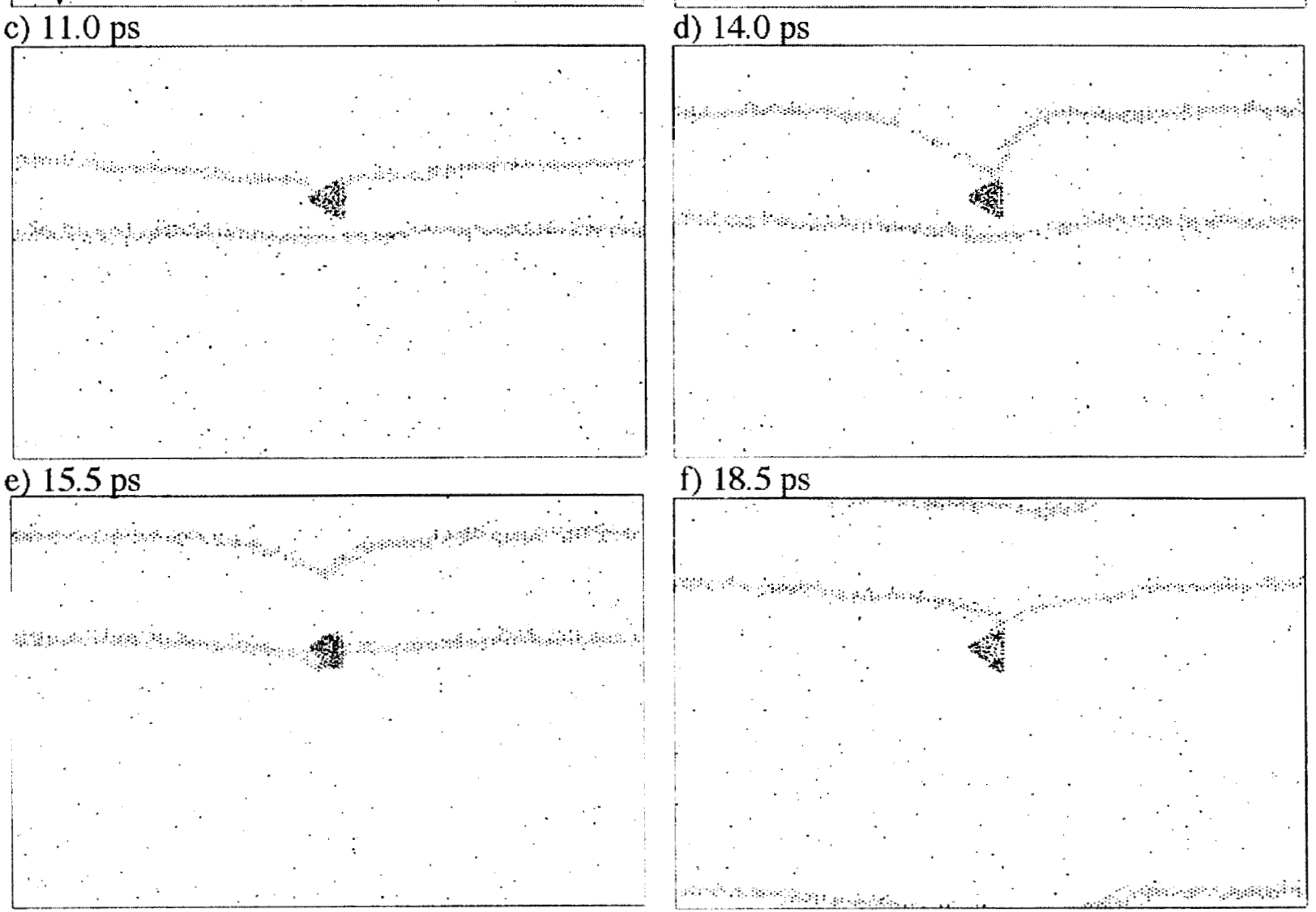

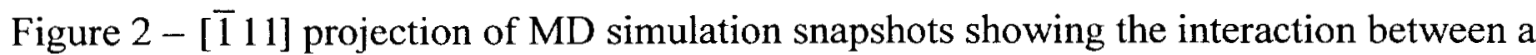
moving, dissociated edge dislocation and an SFT which overlaps the dislocation glide plane, as visualized by plotting atoms with high potential energy. Dislocation positions are shown at a) 0.0 ps, b) $9.0 \mathrm{ps}$, c) $11.0 \mathrm{ps}$, d) $14.0 \mathrm{ps}$, e) $15.5 \mathrm{ps}$ and f) $18.5 \mathrm{ps}$ after applying a $300 \mathrm{MPa}$ shear stress. Note, the use of high potential energy atoms for visualization introduces thermal noise (isolated points) into the snapshots. 
a) $0.0 \mathrm{ps}$

\section{$<111>$ projection}

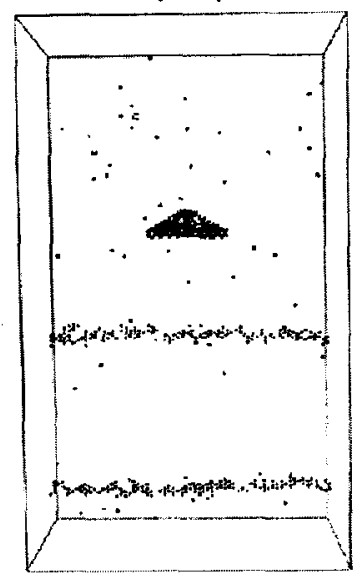

$<110>$ projection

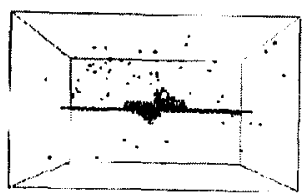

b) $11.0 \mathrm{ps}$
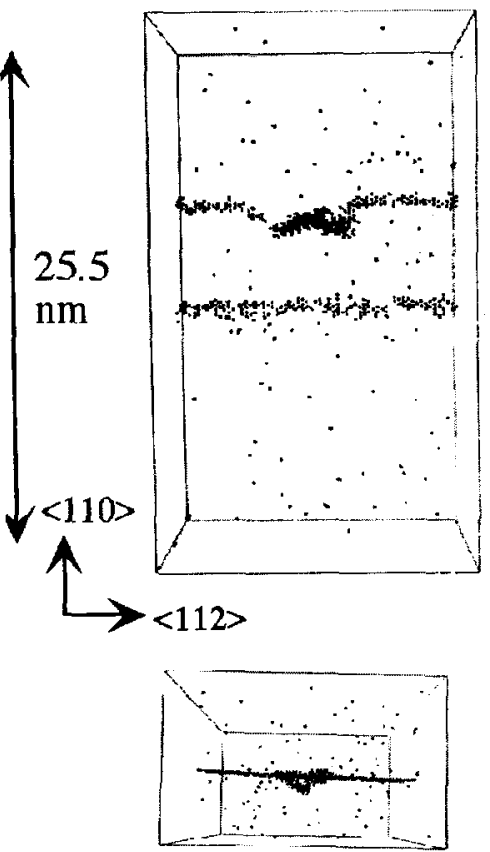

c) $16.0 \mathrm{ps}$

d) $19.0 \mathrm{ps}$
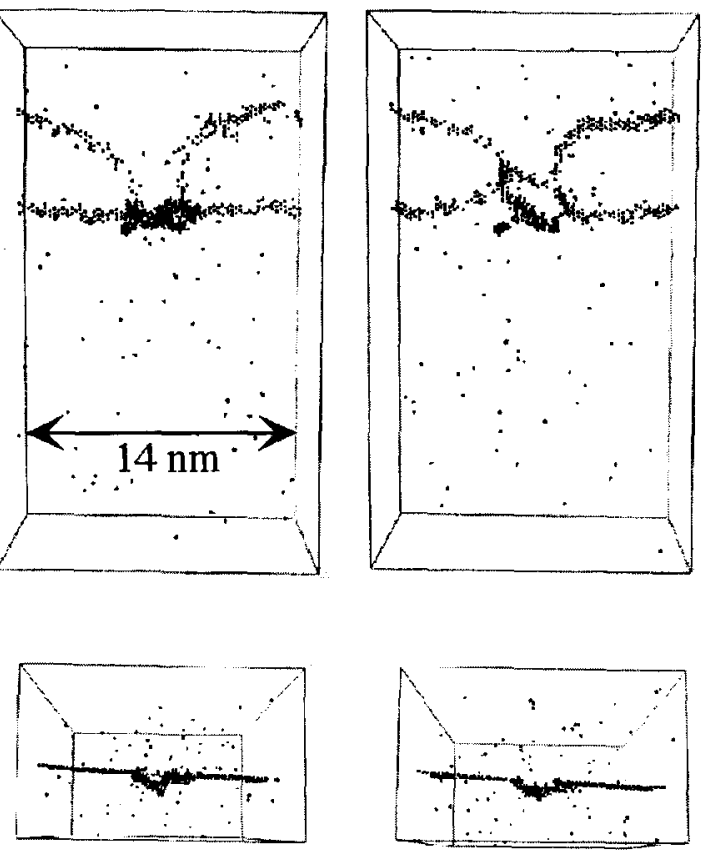

Figure 3 - MD simulation snapshots showing the interaction between a moving, dissociated edge dislocation and an overlapping, truncated SFT in $\mathrm{Cu}$. The high potential energy atoms are visualized in $<111>$ (top) and $<110>$ (bottom) projections and show the motion of the two Shockley partials and interaction with the overlapping, truncated SFT at a) 0, b) 11.0, c) 16.0 and d) $19.0 \mathrm{ps}$ after application of a $300 \mathrm{MPa}$ shear stress. See text for additional details.

The detailed absorption mechanism is complicated and has not yet been completely analyzed. It is clear that passage of a single dislocation through a perfect SFT will not lead to its absorption, but it is not yet known how many dislocations are required to completely shear a SFT, or what degree of SFT truncation will result in absorption. However, it is clear that defect absorption produces dislocation climb and the formation of superjog pairs, which have decreased mobility. One of the superjogs is initially constricted, presumably in the form of a Lomer segment, as discussed by Rodney and Martin for the case of dislocation climb associated with self-interstitial cluster absorption [19]. The constricted superjog is essentially sessile, but can transform to a more favorable (glissile) configuration through the incorporation of three selfinterstitials, as discussed in Ref. 19. This process occurred just prior to the snapshot shown in Fig. 3c, and indeed, the small cluster of high energy atoms seen below the left superjog in Fig. 3d has been identified to consist of three vacancies. 


\section{CONCLUSIONS}

Selected results from a MD simulation study of the interaction between a moving edge dislocation and stacking fault tetrahedra defects have been presented. The results show that a perfect SFT acts as a hard obstacle for dislocation motion and, although the SFT is sheared by the dislocation passage, it remains largely intact. However, our simulations show that an overlapping, truncated SFT is absorbed by the passage of an edge dislocation, resulting in dislocation climb and the formation of a pair of less mobile super-jogs on the dislocation. Additional simulations are underway to characterize the matrix of possible dislocation-SFT interactions, including the effect of applied stress and stacking fault energy, and provide rules for dislocation dynamics simulations that can provide insight into the mechanisms responsible for flow localization in irradiated metals.

This work was performed under the auspices of the U.S. Department of Energy by University of California Lawrence Livermore National Laboratory under contract No. W-7405-Eng-48.

\section{REFERENCES}

1. L. K. Mansur and E. E. Bloom, J. of Metals, 34 (1982) 23.

2. G. E. Lucas, J. Nuc. Mat. 206 (1993) 287.

3. B. N. Singh and S. J. Zinkle, J. Nuc. Mat.. 206 (1993) 212.

4. $\quad$ H. Trinkaus, B. N. Singh and A. J. E. Foreman, J. Nuc. Mat. 251 (1997) 172.

5. M. Victoria, N. Baluc, C. Bailat, Y. Dai, M. I. Luppo, R. Schaublin and B. N. Singh, J. Nuc. Mat. 276 (2000) 114.

6. Y. Dai, M. Victoria, Mat. Res. Soc. Symp. Proc., 439 (1997) 319.

7. $\quad$ N.M. Ghoniem, S.-S. Tong and L.Z. Sun, Phys. Rev. B, 139(1) (2000) 913.

8. T. Diaz de la Rubia and M. W. Guinan, Phys. Rev. Lett. 66 (1992) 655.

9. W. J. Phythian, R. E. Stoller, A. J. E. Foreman, A. F. Calder and D. J. Bacon, J. Nucl. Mat. 223 (1995) 245.

10. R. S. Averback and T. Diaz de la Rubia, Solid State Physics, 51 (1998) 281.

11. Y. N. Osetsky, D. J. Bacon, A. Serra, B. N. Singh, and S. I. Y. Golubov, J. Nucl. Mat. 276 (2000) 65.

12. B. D. Wirth, V. Bulatov and T. Diaz de la Rubia, J. Nuc. Mat. (2000) in press.

13. M. J. Caturla, N. Soneda, E. A. Alonso, B. D. Wirth and T. Diaz de la Rubia, J. Nuc. Mat. 276 (2000) 13.

14. J. Silcox and P. B. Hirsch, Phil. Mag., 4 (1959) 72.

15. Y. N. Osetsky and D. J. Bacon, this conference proceedings.

16. T. Diaz de la Rubia and M. W. Guinan, J. Nuc. Mat., 174 (1990) 151.

17. S. M. Foiles, M. I. Baskes and M. S. Daw, Phys. Rev. B, 33 (1986) 7983.

18. M. Ghaly and R. S. Averback, personal communication.

19. D. Rodney and G. Martin, Phys. Rev. B 61 (2000) 8714. 